\title{
A (de)colonialidade do patrimônio na América Latina: lugares do negro e do indígena no caso brasileiro e argentino ${ }^{1}$
}

\author{
La (de)colonialidad del patrimonio en América Latina: lugares del negro y \\ del indígena en el caso brasileño y argentino
}

\author{
The (de)coloniality of heritage in Latin America: places of black and \\ indigenous in the Brazilian and Argentine case
}

\author{
Loudmia Amicia Pierre-Louis ${ }^{2}$ \\ Bárbara Ferreira de $\operatorname{Lima}^{3}$ \\ Félix Ceneviva Eid ${ }^{4}$
}

\begin{abstract}
Resumo
Este trabalho pretende analisar a conformação do campo patrimonial no Brasil e na Argentina, durante os séculos XIX e XX, no conjunto de representações e práticas que o definem na América Latina. Delineia-se o panorama de reivindicações sócio-políticas dos movimentos de luta negros e indígenas que reconfiguram, a partir de uma perspectiva (de)colonial da história, tais políticas patrimoniais no século XXI. A invenção dos Estados-Nação e a conformação do campo patrimonial são correlatos. A patrimonialização é instrumento de criação de narrativas nacionais enunciadas pelo poder público. Dessa forma salienta-se os conceitos civilizatórios, trazidos pela modernidade eurocêntrica, presentes nos estatutos do Instituto Histórico e Geográfico Brasileiro (IHGB), posteriormente sucedido pelo Instituto do Patrimônio Histórico e Artístico Nacional (IPHAN), para o caso brasileiro, e da Comisión Nacional de Museos y Monumentos y Lugares Históricos (CNMMYLH) para o caso argentino. São estes os órgãos estatais responsáveis pela institucionalização do silenciamento de memórias sociais e identidades coletivas, em detrimento da construção de uma única, a branca cristã. Observando, neste sentido, as dinâmicas de (re) apropriação e transformação no tempo das práticas culturais e como organizações em movimentos sociais, estes grupos subalternizados demandam novas concepções de cultura e patrimônio imaterial, mostrando, como resultado, a pluralidade cultural. As massas e as manifestações populares, esses setores historicamente excluídos, são valorizados e passaram a ser simbolicamente representados nestas nações.
\end{abstract}

Palavras-chave: América Latina; Argentina; Brasil; (De)colonialidade; Patrimônio.

\section{Resúmen}

\footnotetext{
1 Artigo apresentado no Simpósio Temático JOVENS PESQUISADORES LATINO-AMERICANOS durante o II Seminário Latino-Americano de Estudos em Cultura - SEMLACult em Foz do Iguaçu/PR, Brasil, 2018.
}

\footnotetext{
${ }^{2}$ Estudante de graduação em História - América Latina; Universidade Federal da Integração Latino-Americana; Foz do Iguaçu, Paraná, Brasil; lap.louis.2016@aluno.unila.edu.br.
}

\footnotetext{
${ }^{3}$ Estudante de graduação em História - América Latina; Universidade Federal da Integração Latino-Americana; Foz do Iguaçu, Paraná, Brasil; bfd.lima.2016@aluno.unila.edu.br.

${ }^{4}$ Mestre em Etnomusicologia e Professor da Universidade Federal da Integração Latino-americana; Foz do Iguaçu, Paraná, Brasil; felix.eid@unila.edu.br.
} 
Este trabajo pretende analizar la conformación del campo patrimonial en Brasil y Argentina a lo largo de los siglos XIX y XX, en el conjunto de representaciones y prácticas que lo definen en América Latina. Se traza el panorama de reivindicaciones sociopolíticas de los movimientos de lucha negros e indígenas que reconfiguran desde una perspectiva (de)colonial de la história, tales políticas patrimoniales en el siglo XXI. La invención de los Estados nacionales y la conformación del campo patrimonial están correlacionados. La patrimonialización es un instrumento de creación de narrativas nacionales enunciadas por el poder público. Para ello, se destacan los conceptos civilizatorios traídos por la modernidad eurocéntrica presente en los estatutos del Instituto Histórico e Geográfico Brasileiro (IHGB), posteriormente sucedido por el Instituto do Patrimônio Histórico e Artístico Nacional (IPHAN) en el caso brasileño, y de la Comisión Nacional de Museos y Monumentos y Lugares Históricos (CNMMYLH) en el caso argentino. Son estos los órganos estatales responsables por la institucionalización del silenciamiento de memorias sociales e identidades colectivas, en detrimento de la construcción de una única, la blanca cristiana. Observando en este sentido, las dinámicas de (re) apropiación y transformación en el tiempo de las prácticas culturales y como organizaciones en movimientos sociales, estos grupos subalternizados demandan nuevas concepciones de cultura y patrimonio inmaterial, mostrando, como resultado, la pluralidad cultural. Las masas y las manifestaciones populares, esos sectores históricamente excluídos, son valorizados e pasaron a ser simbólicamente representados en estas naciones.

Palabras-claves: América Latina; Argentina; Brasil; (De)colonialidad; Patrimonio.

\begin{abstract}
This work aims to analyze the conformation of the patrimonial field in Brazil and Argentina along the XIX and XX centuries, in the set of representations and practices that define it in Latin America. It outlines the panorama of socio-political claims of the black and indigenous struggle movements that reconfigure from a (de)colonial perspective of history, such patrimonial policies in the XXI century. The invention of the national States and the conformation of the patrimonial field are correlated. Patrimonialization is an instrument for the creation of national narratives enunciated by the public power. To this end, the civilizatory concepts brought by the Eurocentric present modernity are emphasized, those found in the statutes of the Instituto Histórico e Geográfico Brasileiro (IHGB,) subsequently succeeded by the Instituto do Patrimônio Histórico e Artístico Nacional (IPHAN) for the Brazilian case and the Comisión Nacional de Museos y Monumentos y Lugares Históricos (CNMMYLH) for the Argentine case. These State institutions are responsible for the institutionalization of the silencing of social memories and collective identities, to the detriment of the construction of a single one, the Christian white. Observing, in this sense, the dynamics of (re) appropriation and transformation in time of cultural practices and as organizations in social movements, these subalternized groups demand new conceptions of culture and intangible patrimony, showing, as a result, the cultural plurality. The masses and popular demonstrations, these historically excluded sectors, are valued and became symbolically represented in these nations.
\end{abstract}

Keywords: Latin America; Argentina; Brazil; (De)coloniality; Heritage.

\title{
1. Introdução
}

Os estudos sobre a questão da preservação cultural hão demonstrado como essa prática está intimamente associada à própria formação dos Estados nacionais. As últimas décadas do século XVIII deram nascimento ao patrimônio cultural moderno. Desde a Europa, com o advento da Revolução Francesa, se propaga às repúblicas e monarquias latino-americanas e caribenhas a pretensão de se constituírem como territórios unificados e de se posicionarem como nações civilizadas aos olhos do mundo.

Desse modo, os séculos XIX e XX foram imbuídos pelos processos de patrimonialização que consistem na criação de instituições, na elaboração de leis que garantem o trabalho de preservação, de conservação e de restauração dos bens culturais históricos e artísticos. Este procedimento se expande para a América Latina e o Caribe nos 
anos 30 do século XX: "Atualmente, na grande maioria das legislações nacionais consta o preceito de que é dever do Estado preservar o patrimônio histórico e artístico." (FONSECA, 2005, p.159). Os Estados-nação portanto se caracterizam pela intervenção do Estado no plano da cultura e, especificamente, na questão do patrimônio.

Uma vez que a preservação patrimonial é instrumentalizada para caracterizar e criar conformidade sociocultural às novas nações surgentes, esta ação logo implica na seleção criteriosa de elementos alegóricos que se encarregam de representar o novo corpo nacional (FONSECA, 2005). Assim são arquitetados discursos que classificam as culturas presentes no território, entre as apropriadas e as não apropriadas, para representar a dita nação e conjuntamente associá-las a rememoração de um passado heroico. Assim foram atribuídos aos patrimônios nas ex-colônias, a missão de relembrar o passado ou o legado europeu, branco e católico deixado pelos “conquistadores”, como índice de civilização.

Desta forma, o patrimônio brasileiro nasce como herdeiro das tradições luso-cristãs: "a nova Nação brasileira se reconhece enquanto continuadora de uma certa tarefa civilizadora iniciada pela colonização portuguesa" (GUIMARÃES, 1988, p.6), e esta rememoração do passado colonial não se restringia somente ao sentido figurativo. Aos negros e indígenas foi reservada a incorporação nacional substancialmente motivada pelo interesse econômico, quanto às terras que ocupavam e ao somarem como mão-de-obra laboral. Era pretendido interiorizar a civilização e expandir as fronteiras nacionais. Para o caso argentino a consolidação do patrimônio não se deu de forma diferente. Assentou-se sobre os mesmos preceitos civilizatórios e de progresso que rondavam a mentalidade positivista do século XIX.

Esse quadro histórico muda com o paradigma de inserção dos bens e práticas culturais nos respectivos órgãos que administram o patrimônio nacional, promovido pelas contestações dos grupos que estiveram à margem do protagonismo social na fundação destes órgãos. Esses grupos protestaram em defesa de suas manifestações culturais, inferindo sob o discurso oficial proferido pelos Estados nacionais, a fim de reconhecimento e revalorização histórica.

\section{Brasil, Argentina: Os renegados da pátria}

A monarquia Brasileira - uma vez que se pode falar da nação Brasileira a partir da sua independência em 1822 - necessitava de uma representação imaginária simbólica como suporte, para expressar-se, criar e reforçar, uma consciência nacional antes mesmo da constitucionalização do patrimônio pelo Instituto do Patrimônio Histórico e Artístico Nacional (IPHAN). Esta representação imaginária seria produzida pelo Instituto Histórico Geográfico Brasileiro (IHGB) mediante o uso da história e da geografia. O órgão público 
incentivava e alimentava no brasileiro o sentimento nacionalista de pertencimento ao país e o orgulho forjado no lema do discurso moderno/iluminista de "ordem e progresso". Logo, o projeto brasileiro de nação “... amalgamação muito difícil ... [para juntar o] metal heterogêneo, como brancos, mulatos, pretos livres e escravos, índios etc. etc. etc., em um corpo sólido e político" (GUIMARÃES, 1988, p. 06), será construído à base das tradições luso-cristãs, eliminando o negro e fazendo do índio, um mito fundador. Assim:

Ao definir a Nação brasileira enquanto representante da idéia de civilização no Novo Mundo, esta mesma historiografia estará definindo aqueles que internamente ficarão excluídos deste projeto por não serem portadores da noção de civilização: índios e negros. O conceito de Nação operado é eminentemente restrito aos brancos, ... a Nação brasileira traz consigo forte marca excludente, carregada de imagens depreciativas do outro, cujo poder de reprodução e ação extrapola o momento histórico preciso de sua construção. (GUIMARÃES, 1988, p.7)

A princípio o patrimônio nacional se referia apenas aos bens materiais. O IPHAN ainda nas primeiras décadas de sua fundação - no então SPHAN (Serviço do Patrimônio Histórico e Artístico Nacional), e igualmente o CNMMYLH, se focaram na salvaguarda das heranças arquiteturais e mobiliária do período colonial, na celebração de personagens históricos relacionados à independência e nos eventos significativos desses processos (CONTI, 2009; 2016). Logo, a ausência da representação dos negros e dos indígenas se justificou com o discurso de que essas populações não tinham testemunhos materiais de excepcional valor, já que não eram agentes históricos.

Como lembrado por Paz (2017, p.99), "Os intelectuais defendiam veementemente a inferioridade inata aos homens de cor e a sua inutilidade frente ao projeto de nação que o país elaborava no início do século XX”. E portanto, não se obrava unicamente ao encobrimento dessas populações como também na sua eliminação do projeto de nação. Nesse sentido, os indígenas do território argentino sofrerem com uma política oficial do Estado para sua supressão. Várias campanhas militares, desde a independência de 1810 ao ano de 1917, foram oficializadas em leis com objetivo de tomar suas terras para ampliar as fronteiras do território nacional argentino, além de executar uma limpeza racial. Os negros por sua vez sofreram de um assassinato indireto, como as mortes resultadas da sua participação nas várias guerras travadas pelo Estado argentino e da precariedade socioeconômica que influenciou na alta taxa de mortalidade (GARCÍA, 2010).

Igualmente os indígenas no Brasil eram vistos como obstáculo à soberania da nação, mas, devido ao mito de democracia racial propagado pelo Estado, foram tutelados através de políticas indigenistas - dispositivo de controle dessas populações - que não detinham interesses em resguardar ou valorizar a sociodiversidade daqueles povos, senão atuar pelo 
apagamento de seu modo de ser. Enxergados como seres primitivos, precisavam ser educados para aderir à civilização e aos avanços econômicos da nação. Destarte, a pretensão era de transformá-los, pela assimilação imposta, em índios bons e reabilitados. Inculcando-lhes valores morais e culturais - já que eram encarados como desprovidos destas características - a fim de homogeneizar a cultura branca nacional sobrepondo-a às manifestações culturais e artísticas de outras comunidades e coagindo o abandono das línguas nativas, das práticas religiosas e dos costumes ancestrais. Dito de outra forma "na medida em que os índios iam assimilando a cultura do branco, tinham sua identidade aos poucos silenciada." (DA SILVA et al., 2017, p.5).

Os negros por sua vez eram vistos como o mais abominável, e logo suas práticas culturais também foram relacionadas a esta visão. Seus cantos, danças, e a religião sobretudo, eram criminalizados e perseguidos como incompatíveis à nação civilizada. Um exemplo que pode ser evocado como prática de menosprezo das culturas da população negra, é o acervo do Museu de Magia Negra. Tombado como bens etnográficos em 1938, o acervo consistia em uma coleção de objetos e peças de magia afro-brasileira criada a partir da repressão da Polícia Civil do Rio de Janeiro às manifestações culturais dos afrodescendentes.

Para entender o uso do conceito de patrimônio etnográfico no país, Corrêa (2005) apresenta as bases históricas e conceituais sobre as quais se deu o discurso etnográfico no mundo ocidental. Segundo suas análises, nas últimas décadas do século XIX a etnografia, inspirada nos conceitos do darwinismo social, referia-se ao registro das fases e períodos étnicos da espécie humana no caminho da sua evolução da selvageria e da barbárie à civilização. Por certo, “enquanto os bens e acervos de 'arte-sacra' católica são inseridos nos livros de Tombo Histórico e de Belas-Artes, os bens e acervos de religião e magia populares são classificados como etnográficos" (CORRÊA, 2005, p.410). O autor reconhece que ocorreram várias mudanças no seu uso, porém, “o termo 'etnografia' foi sempre usado sob o peso de sua origem, ligada ao "concerto etnocêntrico das nações europeias"” (MATOS, 1994 apud CORRÊA, 2005, p.426). Desta maneira, ao tombar tal acervo como etnográfico o Estado Brasileiro apresentava o lado atrasado do país, o exótico, o superado e ainda justificava o porquê que certos grupos tinham que ser mantidos à margem da nação.

Enquanto no imaginário brasileiro se fala de mestiçagem e de democracia racial, no caso argentino a identidade nacional se constrói em torno do europeu, o que deu lugar ao imaginário de uma argentinidad totalmente branca. As duas nações trabalharam para o desaparecimento tanto dos indígenas como dos negros, porém como vimos, de forma diferente. Na Argentina houve uma limpeza racial com o assassinato legalizado dos indígenas 
e o fato de "deixar morrer" aos negros, no Brasil o silenciamento se verificou desde uma política de aculturação forçada.

\section{Uma nova investida patrimonial}

As últimas décadas do século XX propiciaram ênfase aos estudos multiculturais. Exalta-se a pluridiversidade em busca de novos entendimentos sobre a identidade e o pertencimento étnico, amplia-se a noção de patrimônio e da participação cidadã. As décadas de 80 e 90 e os primeiros anos do século presente foram pertinentes para o reconhecimento constitucional, o tombamento e registro de patrimônios de ressonância indígena e afro. Para essa mudança na política cultural foi preciso a participação e pressão dos movimentos sociais sob os Estados brasileiro e argentino. Entendemos que o movimento social:

Refere-se à ação dos homens na história. Esta ação envolve um fazer - por meio de um conjunto de procedimentos - e um pensar - por meio de um conjunto de ideias que motiva ou dá fundamento à ação. Trata- se de uma práxis, portanto. (GOHN, 2000, p.12).

Internacionalmente nas últimas décadas do século $\mathrm{XX}$, vários movimentos sociais se articularam para exigir direitos civis, igualdade de gênero e descolonização, como o fim do apartheid na África, a redemocratização dos Estados que encontravam-se em plena ditadura militar e inclusive direitos culturais. Entre as conquistas desses movimentos sociais, deu-se no Brasil nas décadas de 1980, o tombamento dos primeiros patrimônios históricos negro - que são os bens e valores em que se materializam tradições dos afro-brasileiros (SERRA, 2005) em grande razão das pressões dos movimentos negros e das lideranças do povo-de-santo. Falamos do sítio de candomblé da Casa Branca do Engenho Velho e o sítio da Serra da Barriga, parte mais alcantilada. Em outra escala, na década de 1970, líderes indígenas e as primeiras organizações representativas desses povos exerceram forte pressão sobre a política indigenista oficial, contestando a tutela exercida pelo Estado. Como resultado desta pressão e a redemocratização do país após o regime militar, a Constituição Federal de 1988 acaba oficialmente com a tutela e garante os direitos jurídicos e de expressão sociocultural dos povos indígenas, como também dos afrodescendentes e dos quilombolas.

Outra importante conquista na dimensão constitucional brasileira foi o Decreto $\mathrm{N}^{\circ}$ 3.551, de 4 de agosto de 2000, que se insere pontualmente como paradigma que visa atender às demandas de reivindicações e solicitações populares dos principais chefes e professores indígenas. Criam-se o registro de bens culturais de natureza imaterial e o Programa Nacional do Patrimônio Imaterial (PNPI). Temos assim em 2002 o registro como Patrimônio Cultural Brasileiro, pelo Conselho do IPHAN, da arte gráfica kusiwarã. E em 2003, as "Expressões 
gráficas e oralidade entre os Wajãpi do Amapá" foram registradas como Obra Prima do Patrimônio Oral e Imaterial da Humanidade pela UNESCO (GALLOIS, 2006). Foi igualmente por decreto propiciada a formação do Inventário Nacional da Diversidade Linguística (INDL), que, atendendo parcialmente às demandas dos povos indígenas, se reconhece as línguas Guarani M'bya, Talian e Asurini do Trocará como "Referência Cultural Brasileira" (IPHAN, 2018). Nesta perspectiva de políticas de salvaguarda, foram estabelecidos os "registros de bens culturais" orientados para abarcar a dimensão da multiculturalidade presente no território brasileiro.

$\mathrm{Na}$ Argentina, os militantes negros "África Vive” e outros grupos de ativistas afroargentinos conquistaram que esse grupo passasse a ser incluído nos censos demográficos a partir de 2010, após aproximadamente 120 anos de ausência. Outras manifestações de conquista deu-se no tombamento de la Capilla de los Negros, patrimônio histórico nacional de ressonância afro (ANNECCHIARICE 2014, 2018), a nomeação de Maria Remedios del Valle, mulher afro, como mãe da Pátria Argentina, a deliberação do Dia Nacional dos/as Afro-argentinos/as e da Cultura Afro e o reconhecimento institucional dos povos indígenas argentinos na formação cultural e étnica da nação.

\section{4. "Aqui estamos"}

O Terreiro da Casa Branca do Engenho Velho em Salvador/BA é tradicionalmente considerado o mais antigo templo afro-brasileiro. Os seus anos de funcionamento sofrem discordância segundo as fontes, conforme uma reportagem publicada em 1974 pelo jornal "Folha de São Paulo" como nos lembra Serra (2005), o templo tinha nada mais e nada menos que 365 anos. Enquanto, o jornal "A Tarde" por sua vez fala de 150 anos em uma publicação do ano de 1983 e posteriormente no ano de 1985 estabelecia 300 anos.

O que de certo se pode afirmar é que na crença popular baiana sobretudo, esse templo ocupa um lugar importante, e sua antiguidade é incontestável. Assim, a importância política do longo processo de tombamento do Terreiro - apesar de ser tombamento em 1984, oficialmente o terreno passou a ser propriedade do povo-de-santo em 1985 e foi homologado como patrimônio Arqueológico, Etnográfico e Paisagístico, e Histórico, em 1986 - é notável. O "valor da [sua] preservação, onde se manifesta expressão cultural de significativa parcela da população nacional de origem africana, cujos antepassados participaram desde a fase inicial da formação brasileira" (IPHAN, Processo "T" 1067-T82, p.111, apud PAZ, 2017, p.104) se fez indubitável pelo Estado. 
Ressaltamos, como visto em Serra (2005) que o processo de tombamento do Terreiro esteve intrinsecamente relacionado com a mobilização de lideranças negras de todo o país, dos representantes de diversas organizações antirracistas, de pessoas e grupos envolvidos nas lutas pelos direitos humanos, de membros e líderes de comunidades negras tradicionais, e de várias entidades da sociedade civil que souberam se posicionar e defender os valores e o tombamento do patrimônio negro do Brasil contra argumentos desfavoráveis do Estado.

O processo de tombo em 1985 e homologação em 1986 da "Serra da Barriga, parte mais alcantilada" em Maceió/AL, foi igualmente e amplamente defendido por luta dos movimentos sociais. O simbolismo de resistência, de luta em prol da liberdade do povo negro escravizado do principal mocambo (cidade) do Quilombo dos Palmares, o maior das Américas - com uma população de 30 mil habitantes em aproximadamente cem anos - lhe conferiu importância à memória e à identidade nacional. O Quilombo dos Palmares foi declarado Monumento Nacional em 1988, e Zumbi dos Palmares, um de seus principais líderes, foi estimado pelo Estado como herói nacional (IPHAN, 2017).

As pressões exercidas pela sociedade levou o Estado Brasileiro a se comprometer com uma reparação simbólica para com os marginalizados da sua história oficial e essa busca de reparação extrapolou as fronteiras nacionais. O Sítio Arqueológico Cais do Valongo foi construído em 1811, na antiga área portuária do Rio de Janeiro, onde desembarcaram cerca de 1 milhão de africanos escravizados para a América do Sul. Marco físico mais importante da chegada de escravizados negros no continente, o Cais do Valongo é um exemplo de sítio histórico que desperta as memórias da escravidão moderna. Por conseguinte, foi inscrito no ano passado na lista de patrimônio cultural mundial da UNESCO (UNESCO, 2017) e igualmente foi reconhecido como patrimônio cultural do MERCOSUL no mesmo ano (IPHAN, 2017).

O Estado Argentino tem tentado também reparar os danos das suas políticas de apagamento aos negros e indígenas. Foram nomeados alguns patrimônios culturais afroargentinos como la Capilla de los Negros em Chascomús, na província de Buenos Aires, e em relação às manifestações e expressões afro como o tango, milonga, candombe e payada (UNESCO 2011 apud ANNECCHIARICO, 2014).

A Capilla de los Negros foi declarada em 1962 patrimônio histórico nacional e em 2011 foi reconhecida pela UNESCO como "sitio histórico de la memoria de la ruta del esclavo en el Río de la Plata". Considerada um dos poucos testemunhos materiais a nível nacional e internacional da presença dos afro-argentinos - local de encontro da população afro, para festejar e praticar suas religiosidades - a Capilla ainda hoje está em funcionamento 
desde 1862 e mantida pelos descendentes de seus fundadores da Hermandad de Morenos Bayombé de Anvensa.

Mesmo que as identidades do negro e do indígena incorporem significados diferentes segundo a sociedade, o que salientamos neste trabalho é exatamente a pressão exercida pelos grupos de movimentos sociais indígenas e afro tanto no Brasil como na Argentina. Desde os anos de 1970 frente ao Estado objetivaram aumentar suas visibilidades e exigir direitos para uma reparação simbólica para que deixassem de ser os excluídos e passassem a serem vistos como componente igualmente importante das ditas nações. Pois, como declarou Soledad Luis - descendente dos fundadores da Capilla, guia turística do município de Chascomús que trabalha para promover a cultura e história dos afrodescendentes - "A capela é a nossa referência, aqui podemos mostra a verdade, ou seja, aqui estamos" (Soledad Luis, programa de Televisão Pública "Eu moro na Argentina", 24/11/2012, disponível online apud ANNECCHIARICO 2018. Tradução nossa).

Pensar o patrimônio na América latina é pensar as relações étnico-raciais, saber a importância do lugar dos bens culturais de matriz africana e indígena entre os bens representativos da memória nacional. Esse exercício nos permite problematizar, nesse caso particular, a narrativa hegemônica da democracia racial brasileira e da nação branca argentina. As mudanças observadas nessa parte do trabalho se refere às políticas de patrimônio cultural, e podem ser analisadas a partir de uma narrativa decolonial.

\section{Uma análise decolonial}

A colonialidade do poder, do ser, do saber originada pelo colonialismo nas Américas e reforçada pelas teorias racistas como o darwinismo social e incrementadas pelo positivismo hão levado os governos dessa região a adotarem políticas de embranquecimento, favorecendo a imigração europeia para a diminuição e mesmo supressão das populações originárias e afro. Ao não serem representados através de patrimônios ou apresentados como seres exóticos ou superados, os negros e indígenas foram levados ao desaparecimento, pois, não eram o "ideal de cidadão" que os Estados aspiravam.

Assim, Achille Mbembe (2016, p.130) evidencia que "qualquer relato histórico do surgimento do terror moderno precisa tratar da escravidão, a primeira instância da experimentação biopolítica" que se dá com a divisão das pessoas em raças, estabelecendo quais devem viver e quais não, estando a raça sempre presente nas práticas de poder do ocidente para desumanizar os povos e poder dominá-los (FOUCAULT 1997, apud MBEMBE, 2016). 
Os novos Estados-nação latino-americanos e caribenhos ao se independentizarem apenas articularam a colonialidade do poder sobre novas bases institucionais, sendo a principal delas, a consolidação do próprio Estado-nação. Nesse caso, a soberania por meio do racismo presente em todos os Estados modernos define quem importa e quem não importa, quem é "descartável” e quem não é. Consequentemente, para o filósofo camaronês (MBEMBE, 2016) - do mesmo modo que os decoloniais - a modernidade foge das análises que a confere o aspecto democrático, da razão, da autonomia e por conseguinte, do começo do bem estar da humanidade e propõe o conceito de necropolítica para nos explicar a relação entre Política, soberania e a morte - produtos da modernidade - como relações de extrema violência e de morte em massa.

Os estudos decoloniais (DUSSEL, 2005; 1994, QUIJANO, 2005; 2007 MIGNOLO, 2007; 2017) partem do pressuposto de que a modernidade se deu juntamente com o colonialismo desde o primeiro contato Europeu com a América. Caracterizada pelos discursos "legitimadores" de civilização e de progresso, a modernidade fazendo-se uso da noção de humanismo marca uma série de práxis extraordinariamente desumanas. Além da modernidade ser “[...] uma máquina geradora de alteridades que, em nome da razão e do humanismo, exclui de seu imaginário a hibridez, a multiplicidade, a ambiguidade e a contingência das formas de vida concretas" (CASTRO-GOMEZ apud BRAGATO, 2014, p. 222 apud ROMAGUERA et al, 2014. p. 22), que se mantém nas relações políticas e culturais excludentes do sistema mundial contemporâneo (SOUSA SANTOS, 2007 apud ROMAGUERA et al, 2014). Pois, conforme Quijano (2007) o colonialismo se refere à dominação política formal, direta, de uma sociedade sobre outra, à ocupação territorial, enquanto a colonialidade se estende além dessa ocupação territorial. A colonialidade portanto é a dominação da cultura ocidental europeia sobre as demais culturas; tratando-se da colonização dessas culturas, do imaginário desses povos, do controle da intersubjetividade, do conhecimento. Sendo efeitos da modernidade, o Estado-nação e o processo de patrimonialização carregarem todo o significado da violência desta modernidade, desde a morte simbólica como a própria supressão dos corpos indesejáveis.

As experiências brasileira e argentina, na institucionalização da proteção de bens culturais, - apesar das suas especificidades na constituição dos Estados-nação - podem ser tomadas como modelo de escolha e exclusão de culturas, de memórias e de identidades. Uma leitura decolonial nos ajuda a entender o porquê destas exclusões na formação dos Estados nacionais latino-americanos e caribenhos. Pois, como visto "a partir da colonialidade é que se articularam o conjunto de narrativas nacionais que, desde o século XIX, vêm forjando as 
identidades coletivas na América latina, reproduzindo mecanismos geradores de alteridades e subjetividades subalternas" (CASTRO-GOMEZ, 1998 apud AMARAL, 2015, p.19). Ao mesmo tempo que "o conceito de colonialidade e a proposta decolonial têm aberto a possibilidade de reconstrução de histórias silenciadas, subjetividades reprimidas, linguagens e conhecimentos subalternizados pela ideia de totalidade definida pela racionalidade moderna" (AMARAL, 2015, p.20). Portanto, o pensamento decolonial visa lutar não para a desocupação territorial das colônias, uma vez que isso já foi feito, mas sim para o processo de ressignificação a longo prazo, que não se limita a um acontecimento jurídico-político, mas que busca uma heterarquia entre as várias relações raciais, étnicas, sexuais, epistêmicas, económicas e de género (GROSFOGUEL, 2005 apud CASTRO-GOMEZ; GROSFOGUEL, 2007).

\section{Conclusões}

Este trabalho analisa qualitativamente, por meio de fontes bibliográficas e dos estudos decoloniais a conformação do campo patrimonial no Brasil e na Argentina durante os séculos XIX e XX, e a consequente formação dos Estados-nação diante de suas inclusões e exclusões na América Latina. Embora toda a América Latina tenha sofrido uma invisibilização dos povos indígenas e africanos, há diferenças importantes nas configurações de cada Estadonação, e este trabalho não dá conta nem pretende abranger. Porém, a reflexão sobre os dois casos aqui tratados pode, junto com outras pesquisas, ajudar a pensar nesta questão como uma problemática geral da América Latina e Caribe.

O objetivo principal é mostrar como pela organização em movimentos sociais os negros e indígenas territórios brasileiro e argentino puderam ter suas identidades e contribuições inseridos na representação nacional, descolando a condição dos Estados-nação como homogêneos culturalmente para uma realidade mais pluricultural. Não descartamos os acontecimentos internacionais relacionados aos convênios e decretos da ONU, UNESCO etc., apesar dos vários questionamentos e críticas que podemos fazer a respeito. Ao mesmo tempo nos perguntamos sobre a possibilidade do patrimônio ser decolonial em Estados modernos.

Essas iniciativas de tombamento e registro de patrimônio se inserem nas tentativas do Estado em lutar contra o preconceito e o racismo, para incluir e dar visibilidade a seus grupos sociais historicamente marginalizados? Como visto, teve sim uma nova investida patrimonial na Argentina e no Brasil, ao serem tombados e registrados bens de ressonância afro e indígena, dando lugar a narrativas outrora silenciadas, reprimidas e subalternizadas. No entanto, o que se observa é que apenas foi aberto um espaço específico para os patrimônios 
negros e indígenas na principal categoria patrimonial branca, que permanece com um status especial. Nos inteiramos por Annecchiarico (2018) que apesar da Capilla de los negros fazer parte do tour oferecido pelo município, e de carregar todo o significado já visto, a presença de afrodescendentes na história da cidade é praticamente ausente do relato oficial. Podemos dizer então que esses tombamentos e registros por parte do Estado, não são necessariamente motivados pela inclusão dos negros e indígenas na história oficial. A modernidade portanto, continua exercendo sua violência inata mediante o Estado contra os seus excluídos (Atlas da Violência 2018), (CIMI, 2017).

\section{Referências}

ANNECCHIARICO, Milena. El patrimonio cultural afro-argentino: un análisis del programa "ruta del esclavo" UNESCO en Argentina. Revista del Museo de Antropología. Facultad de Filosofía y Humanidades - Universidad Nacional de Córdoba - Argentina. jun. 2018.

Disponível em:

$<$ https://revistas.unc.edu.ar/index.php/antropologia/article/view/17543/20211 >. Acesso em $15 / 12 / 18$

ANNECCHIARICO, Milena. "Patrimonio cultural afroargentino: trayectorias, estudios y desafíos". Actas XII Conferencia internacional antropología. Instituto Cubano de Antropología, La Habana. 2014. Disponível em: $<$ https://www.academia.edu/25131186/Patrimonio_cultural_afroargentino_trayectorias_es tudios_y_desaf\%C3\%ADos.Actas_XII_Conferencia_internacional_antropologi_a_Instituto Cubano_de_Antropologi_a_La_Habana._2014>. Acesso em 18/12/2018

AMARAL, João P. Pereira do. Da colonialidade do patrimônio ao patrimônio decolonial. Dissertação (Mestrado) - Instituto do Patrimônio Histórico e Artístico Nacional, Mestrado Profissional em Preservação do Patrimônio Cultural, Rio de Janeiro, 2015.

ATLAS da Violência 2018. Rio de Janeiro: Ipea/FBSP. jun. 2018 Disponível em:< http://www.ipea.gov.br/portal/index.php?option=com_content\&view=article\&id=33410\&Ite

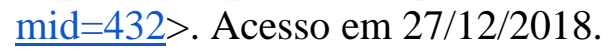

Conselho Indigenista Missionário (CIMI). Violência contra os Povos Indígenas no Brasil: Dados de 2017. Relatório. 2017. Disponível em:< https://cimi.org.br/2018/09/relatorio-cimiviolencia-contra-os-povos-indigenas-no-brasil-tem-aumento-sistemico-e-continuo/>. Acesso em $27 / 12 / 18$

CONTI, Alfredo. La construcción del concepto de patrimonio en Argentina entre 1910 y 1940. Anales LINTA; vol. 4, no. 2. Argentina 2009. Disponível em: $<$ http://sedici.unlp.edu.ar/handle/10915/29088. Acesso em 15/11/2018

CONTI, Alfredo. El patrimonio como representación del "nosotros". El caso de Argentina. Conversaciones, n 2, p. 35-44, jul. 2016.

CORRÊA, Alexandre Fernandes. A coleção museu de magia negra do Rio de Janeiro: O primeiro patrimônio etnográfico do Brasil. Mneme - Revista de Humanidades, v. 7, n. 18, 


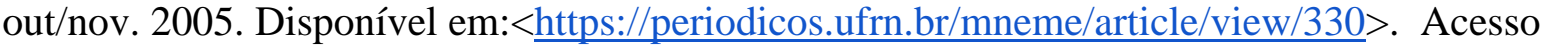
em: jun 2018.

DUSSEL, Enrique. 1492. El encubrimiento del otro. Hacia El origen Del mito de La modernidad. La Paz: Plural Editores, 1994

DUSSEL, Enrique. Europa Modernidade e Eurocentrismo. CLASCO, Buenos Aires, 2005

DUSSEL, Enrique. La colonialidad del saber: eurocentrismo y ciencias sociales. Perspectivas latinoamericanas. CLACSO, Buenos Aires, 2000.

FONSECA, Maria Cecília Londres. "Da Modernização à participação: a política federal de preservação nos anos 70 e 80". Revista do Patrimônio Histórico e Artístico Nacional, Rio de Janeiro, n. 24. Brasília: 1996.

FONSECA, Maria Cecília Londres. O patrimônio histórico na sociedade contemporânea: discurso de posse. RIHGB. Rio de Janeiro: ano 166, n. 428, p. 165-175, jul./set. 2005.

GALLOIS, Dominique Tilkin. Patrimônio cultural imaterial e povos indígenas: exemplos no Amapá e norte do Pará. Iepé, 2006.

GARCÍA, M. I. Los Márgenes de la Nación: Conformación del Estado nacional y construcción de la otredad en la Argentina. VI Jornadas de Sociología de la UNLP. FaHCE. La Plata, Argentina. dec. 2010. Disponible em: $\langle$ http://www.memoria.fahce.unlp.edu.ar/trab_eventos/ev.5084/ev.5084.pdf $>$. Acesso em $18 / 12 / 2018$.

GOHN, Maria da Glória. 500 anos de lutas sociais no Brasil: Movimento social, ONG terceiro setor. Rev. Mediações. Londrina: v. 5, n. 1, p. 11-40, jan./jun. 2000

GUIMARÃES, Manoel Luiz Salgado. "Nação e civilização nos trópicos: o Instituto Histórico e Geográfico Brasileiro e o projeto de uma história nacional”, In: Revista Estudos Históricos. Rio de Janeiro: Fundação Getúlio Vargas, No.1, 1988, pp. 5-27.

GROSFOGUEL, Ramón. "Giro decolonial, teoría crítica y pensamiento heterárquico”. In: Santiago Castro-Gómez y Ramón Grosfoguel (org.). El giro decolonial: reflexiones para una diversidad epistémica más allá del capitalismo global. Bogotá: Siglo del Hombre Editores, 2007

Instituto do Patrimônio Histórico e Artístico Nacional (IPHAN). Inventário Nacional da Diversidade Linguística (INDL). Disponível em: 〈http://portal.iphan.gov.br/indl >. Acesso em: 20 jul 2018.

Instituto do Patrimônio Histórico e Artístico Nacional - IPHAN. Dossiê de tombamento de Candidatura da Serra da Barriga. Parte Mais Alcantilada - Quilombo dos Palmares e Patrimônio Cultural do MERCOSUL Marcelo Brito (coord). São Carlos: Ed. cubo, 2017. Disponível em: <http://portal.iphan.gov.br/uploads/ckfinder/arquivos/Dossie_serra-dabarriga.pdf $>$. Acesso em 25/11/2018. 
LOANGO, Anny Ocoró. Los afrodescendientes en Argentina: la irrupción de un nuevo actor en la agenda política y educativa del país. Revista Colombiana de Educación, N. ${ }^{\circ} 69$. Bogotá, Colombia. 2015.

MBEMBE, Achille. Necropolítica: biopoder soberania estado de exceção política da morte. Arte \& Ensaios n. 32. Rio de Janeiro, UFRJ, dezembro 2016. 123-151 p.

Ministerio de Justicia y Derechos Humanos de la Nación. Secretaría de Derechos Humanos, Derechos de los pueblos indígenas en la Argentina, una compilación. Sebastián Demicheli Calcagno; Viviana Canet; Leticia Virosta (Org.) - 1a ed. Buenos Aires: 2015.

MIGNOLO, Walter D. "El pensamiento decolonial: desprendimiento y apertura un manifiesto". In: Santiago Castro-Gómez y Ramón Grosfoguel (org.). El giro decolonial: reflexiones para una diversidad epistémica más allá del capitalismo global.Bogotá: Siglo del Hombre Editores, 2007. p. 25-46.

MIGNOLO, Walter. COLONIALIDADE O lado mais escuro da modernidade. PUC-Rio, Rio de Janeiro - RJ, Brasil, 2017.

PAZ, F. P. Do "só o espaço" ao lugar de memória. Revista Calundu, v. 1, n. 1, 5 jul. 2017.

QUIJANO, Anibal; WALLERSTEIN Immanuel. La americanidad como concepto, o América en el moderno sistema mundial. Revista Internacional de Ciências Sociais. Vol. XLIV, núm. 4, 1992. p. 583-593.

QUIJANO, Anibal. A colonialidade do saber: eurocentrismo e ciências sociais. Perspectivas latino-americanas. CLACSO, Buenos aires, 2005.

QUIJANO, Anibal. Colonialidad del poder y clasificación social. In: Santiago CastroGómez y Ramón Grosfoguel (compiladores). El giro decolonial: reflexiones para una diversidad epistémica más allá del capitalismo global. Bogotá: Siglo del Hombre Editores, 2007. p. 93-127.

REPRESENTAÇÃO DA UNESCO NO BRASIL. Cais do Valongo é o novo sítio brasileiro inscrito na Lista do Patrimônio Mundial da UNESCO. Jul. 2017. Disponível em:< http://www.unesco.org/new/pt/brasilia/about-this-office/singleview/news/valongo_wharf_is the new_brazilian_site_inscribed_on_unesco/>. Acesso em $17 / 12 / 2018$

ROMAGUERA, D. C. L.; TEIXEIRA, J. P. A.; BRAGATO, F. F. Por uma crítica descolonial da ideologia humanista dos direitos humanos. Derecho y Cambio Social, v. 38, p. 1-27, 2014.

SERRA, Ordep José Trindade. Monumentos negros: Uma experiência. Afri-Ásia, n. 33, p. 169-205. 2005. Disponível em: <https://www.academia.edu/30961618/MONUMENTOS_NEGROS_UMA_EXPERI\%C3\%8

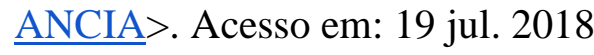



V. 05, ed. especial, mai., 2019, artigo $\mathrm{n}^{\circ}$ 1496 | claec.org/relacult | e-ISSN: 2525-7870

SILVA, M. G. C.; SILVA, M. I. L.; SILVA, V. A. C.. A influência do processo de assimilação e aculturação na formação da identidade dos povos indígenas no Brasil.

CONEDU, 2017. 